pamphlet published in June 1991 by the Committee of Vice-Chancellors and Principals which states that universities face an insidious decline in the standards of teaching and research. He said that universities should take their case to the voters and only by doing so will they "prevent the decline of the university system". In addition, the science lobby in the UK should take advantage of cuts in military expenditure in the UK. This has already happened in the US. In the current fiscal year, the budget for civilian research and development (R \& D) has increased by $10.7 \%$ (or $6 \%$ after inflation) while defence-related R \& D has taken a cut for the second year in a row.

Third, the MRC should broaden its collaboration to include the charities and other research bodies in the development of a comprehensive medical research strategy (Advisory Board for the Research Councils, 1986; British Medical Association, 1990).

AdVISORY BOARD fOR tHE RESEARCH COUNCILS (1986) Report of the Working Party on the Private Sector Funding of Scientific Research (Mathias Committee). London: ABRC.

Dickman, S. \& Aldhous, P. (1991) Helping Europe in human genome research - more coordination needed. Nature, 350, 261.

SMITH, R. (1991a) Strangling the future: the government neglects research at the nation's peril. British Medical Journal, 302, 977-978.

(1991b) Science in Australia: alive, well, kicking and growing. British Medical Journal, 302, 840-842.

Michael MORRIS

Department of Medical and Molecular Genetics Indiana University Medical Centre

975 West Walnut Street

Indianapolis

Indiana 46202-5251

\section{Pathological jealousy defined}

SIR: Mullen's account of jealousy (Journal, May $1991,158,593-601$ ) demonstrates the perils of travel through the soul. Without a careful eye on ambivalence one gets lost. The answer to a question he poses can be simply stated: desire for rivalry is the hallmark of pathological jealousy, separating it from zealous engagement in and solicitous guarding of a relationship (normal jealousy). The Concise Oxford Dictionary definition is "jealous - fiercely protective (of rights etc.); afraid, suspicious or resentful of rivalry in love or affection".

Mullen refers to Freud (1955) but misunderstands - projection and reaction formation are not burdens for jealousy as he laments - they are fuels propelling zeal into the realm of disease. Within pathological jealousy lies concealed the wish for a rival to enter or challenge the relationship. Within non-pathological jealousy lies the wish to preserve the relationship. Both forms usually coexist.

How can anyone wish for a rival? Generally these desires fall into three groups (Freud, 1955a,b):

(a) Oedipal, where rivalry enhances the parentlike qualities of the spouse

(b) Homosexual, where rivalry or unfaithfulness permit a less distressing form of awareness of one's own fondness for someone of the same sex

(c) Narcissistic, where one's own self-representation is enhanced by rival's attention to spouse.

These are some ways. There are others. Pathology is proportional to the amount of one's self one sees in the jealousy-provoking situation. What about envy? Looking carefully at individual cases we see it does not occur without self-investment (projection). Sadness and grief do. By understanding the psychodynamics of a given case with an eye on the above and other ambivalent contents, one can separate pathological jealousy from relationship-affirming solicitousness. Once the central discriminant is established, subsidiary questions like "how much zeal is ok?", answer themselves.

FreUd, S. (1955a) Three contributions to the theory of love. In Standard Edition, vol. I/ (ed. J. Strachey), pp. 163-208. London Hogarth Press.

Freud, S. (1955b) Some neurotic mechanisms in jealousy, paranoia and homosexuality. In Standard Edition, vol. II (ed. J. Strachey), pp. 221-232. London: Hogarth Press.

Medical Center of Hospital of Vermont
Burlington

RICHARD KAST

Vermont, USA

\section{Access to health records}

SIR: Gaitonde (Journal, July 1991, 159, 164) is right to draw our attention to the likely impact of the Access to Health Records Act, 1990, but his pessimistic conclusion that record keeping may be inhibited to the detriment of patient care is disappointing. His prediction of a defensive response from the profession may well come true and was documented in response to the UK Data Protection Act (1987) by Jones et al (1988). These authors audited the censoring of information disclosed to patients by doctors in computerised records in a diabetic clinic and found that $69 \%$ of the problems which had been censored out could, on 
closer scrutiny, be reinstated and disclosed. Such a defensive response to patients having access to records is not inevitable and there are well documented examples from general practice (e.g. Baldry, 1986) and psychiatry (Essex et al, 1990) where actively encouraging patients to share the medical record has been a positive experience for both doctors and patients. Such sharing was entirely compatible with responsible medical practice and supplementary 'confidential' records were unnecessary.

Lipsitt (1980) discussed patient and doctor responses to the introduction of Chapter 214 of the Massachusetts Acts of 1979 which guaranteed patients in the USA access to their records. He noted that few patients sought access to their records despite having the right to do so, and suggested that the traditional doctor-patient relationship, modelled on the parent-child interaction, carries subtle cues which define who will control and who will be controlled. Many doctors found the idea of patients having access to their records threatening to the balance of this relationship and label those who break the taboo and ask to see their records as deviant. Lipsitt warned that attitudes and traditions in medical care are more likely to be modified by an awareness of patients and their feelings than by an incantation of laws.

Gaitonde underplays the potential benefits to patients of the new legislation. Ellis (1979) showed that giving medical patients written information about their conditions significantly improved understanding and recall. An efficient way of providing such information is in the form of a patient-held record which the doctor writes in and the patient keeps. Essex et al (1990) have reported the use of such a record with psychiatric patients receiving care shared between general practice and out-patients. They found that the record was enthusiastically accepted by patients who valued being consulted and thought they were in a better position to challenge their doctor. The record also improved communication between staff. Despite the obvious benefits of the system, these authors also reported a negative response by most psychiatrists and nurse managers consulted.

Patients today expect more information and a more collaborative working arrangement with their doctor. This trend is reflected in the current legislation and is likely to grow in the future. The profession can react to this trend either defensively to maintain the traditional paternalistic approach to patients, or by viewing it as a way of forging a closer relationship with the patient and adding it to their therapeutic armoury. If the latter is to apply, doctors will have to learn how to write records in a manner which patients will understand, and record information which is useful to the patient as well as to professionals. Rather than inhibiting record keeping this would result in an enriched record and improved patient care. Teaching doctors how to write such records should become an important element in undergraduate and postgraduate education and offers a particular challenge to psychiatry. It is a challenge which should be taken up sooner rather than later.

Baldry, M., Cheal, C., Fisher, B. el al (1986) Giving patients their own records in general practice: experience of patients and staff. British Medical Journal, 292, 596-597.

Ellis, D. A., Hopkin, J. M., et al (1979) "Doctors' orders": controlled trial of supplementary, written information for patients. British Medical Journal, Feb 17, 456.

EsseX, B., DoIG,R. \& RENSHAW, J. (1990) Pilot study of shared care for people with mental illnesses. British Medical Journal, 300, 1442-1446.

JoNes, R. B., Hedley, A. J., AlLISON, S. P., et al (1988) Censoring of patient-held records by doctors. Journal of the Royal College of General Practitioners, 38, 117-118.

LIPSITT, D. R. (1980) The patient and the record. New England Journal of Medicine, Jan 17, 168-169.

Department of Psychiatry

Paul Mclaren

Guy's Hospital

London SEI 9RT

\section{Anorexia nervosa in Asian children}

SIR: Bryant-Waugh \& Lask (Journal, February 1991, $158,229-233$ ) have reported cases of anorexia nervosa (AN) in Asian children which, although interesting, are not the first, as Badrinath (Journal, April 1990, 156, 565-568) and Neki et al (1977) have also reported similar cases.

The earlier report by Badrinath has generated a lively discussion to which we would like to add some of our own experiences with AN in India.

Although AN may be less common in India than in the West, it is not as rare as these reports suggest. Indeed, a likely explanation for the absence of reports in literature is the familiarity of the diagnosis rather than its rarity.

At our general hospital psychiatry department, we have encountered five new cases of $A N$ in the last four years. With the average annual intake of about 2500 new patients, the frequency of presentation is quite similar to that reported by Buhrich (1981) in Malaysia. All were unmarried females aged between 13 and 25 years. Contrary to the experience of Khandelwal \& Saxena (Journal, November 1990, 157,784 ), three of our patients did have body image disturbance while none had associated hysterical symptoms. 